\title{
Research of the distributed power system dynamic voltage restorer simulation based on DSP LI Xiao-xia
}

\author{
(. Hunan Railway Professional Technology College, ZhuZhou Hunan 412001)
}

Keywords: PFC, inverter, SPWM, phase-locked, DSP.

\begin{abstract}
This paper aims to design a distributed grid simulation system dynamic voltage restorer means to solve the problem of dynamic energy security in case of equipment operating in the electricity voltage sag or interruption. Means the use of "DC - AC" and "AC - DC - AC" dual structure, control system uses TMS320F28335 to control core sampling method within the rules and DSP chip EPWM module functions to achieve SPWM wave, after hardware and software design, the test of the PFC link device, the power factor was close to 1; a small error SPWM modulation algorithm approximation introduced DC voltage fluctuation detection circuit and AD converter error. POST, input under-voltage and output over-current protection, over-current, under-voltage troubleshooting can automatically restore.
\end{abstract}

\section{Introduction}

In this paper, a dynamic voltage restorer experimental device, a "DC - AC" and "AC - DC - AC" dual structure, the first stage power factor correction (PFC) circuit, its role is to complete the AC DC conversion,It can improve the input side of the power quality. The second stage is a single-phase full-bridge inverter topology plus output transformer. Full-bridge inverter control through DSP dead zone control, to prevent direct access for distributed grid dynamic voltage restorer analog system.

\section{Overall program}

DVR topology shown in Fig. 1. It mainly consists of the active filter and the inverter device, DVR and the inverter device, constitute the critical load. Energy storage unit and a two-stage public interface, the system is running, if the voltage is normal, DVR devices do not compensate for the amount of voltage to the injection system, the device itself is very low power consumption in the standby state. When the dynamic voltage drop and other problems arise, DVR means instant start, to put the circuit compensation, ensure that the voltage is normal. When the voltage is restored, DVR device back to standby.

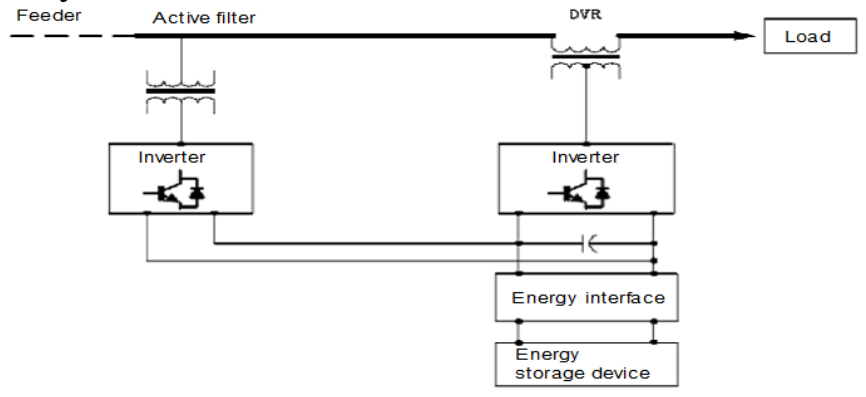

Fig.1 DVR topology

Design uses TMS320F28335 as a controller, which has a programmable dead-time control function, which prevents bridge driver circuit to produce upper and lower leg straight and burned. At the same time can generate SPWM signal to generate SPWM waves through regular sampling method, the symmetry regular sampling algorithm is shown in Fig. 2. Fig.2 can be obtained: 


$$
\left\{\begin{array}{l}
t_{\text {off }}=\frac{T_{s}}{4}\left(1-M \sin \omega t_{1}\right) \\
t_{\text {on }}=\frac{T_{s}}{4}\left(1+M \sin \omega t_{1}\right)
\end{array}\right.
$$

The Pulse width:

$$
t_{p w}=\frac{T_{s}}{2}\left(1+M \sin \omega t_{1}\right)=\frac{T_{t}}{2}\left(1+M \sin \omega t_{1}\right)
$$

Formula (1), the sampling points. (2), the sampling point in time only to carrier ratio,whereas the ratio has nothing to do with the amplitude modulation, and:

$$
t_{1}=k T_{t}, k=0,1, \ldots, N-1 \text { 。 }
$$

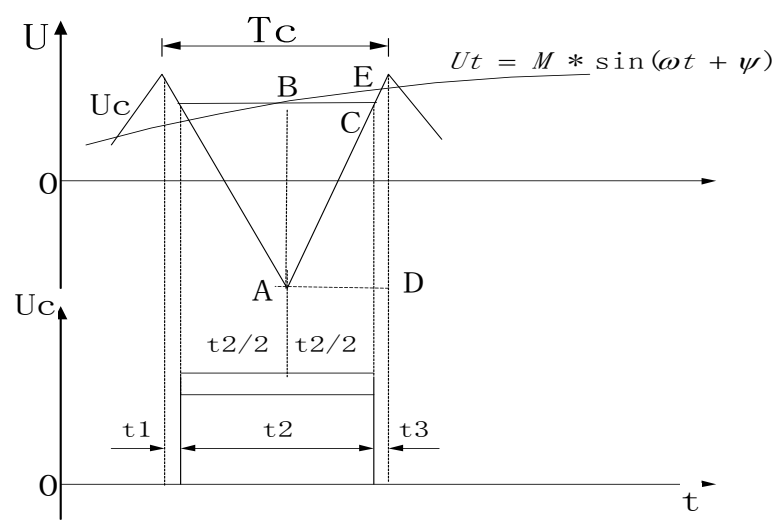

Fig. 2 A schematic symmetry regular sampling algorithm

\section{PFC control method}

System control mode uses average current mode Boost PFC calculated directly from the PFC control circuit parameters are given initial PWM waveform, when the system starts, PI current loop be adjusted, in the realization of the system fast start also avoid starting inrush current sampling noise. In addition, the system samples the moment of starting the input current waveform, while closed-loop control, precise tracking phase, significantly reduce the current distortion.

\section{The Hardware Design}

\subsection{Inductor current conditioning circuit}

Input current conditioning circuit shown in Fig.3. Design uses a resistor current into a voltage signal, and then by the INA282 will pass active filter into the DSP signal amplification after sampling.

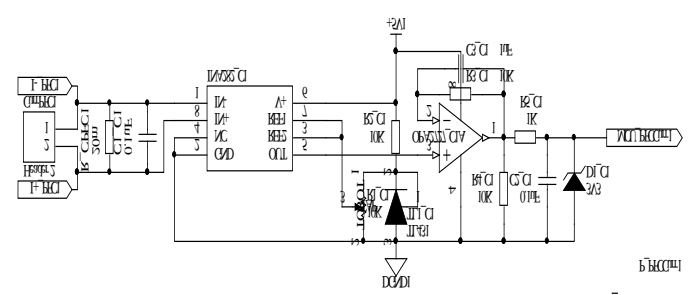

Fig. 3 input current signal conditioning circuit

\subsection{PFC input voltage frequency detection circuit}

The frequency of the input voltage detection circuit shown in Fig.4. First, the input signals using transformer isolation, after a zero comparison and plastic limiter get square wave signal, based on the characteristics of DSP, ECAP captured on the rising and falling edges of the signal only in response to the module, and the amplitude of the signal equally strict requirements (less than 
3.3V), and therefore need sinusoidal signal output into a square wave signal is less than the amplitude of $3,3 \mathrm{~V}$, in the zero crossing, in order not to cause false triggering CAP, zero-crossing switching signal is necessary to avoid oscillation.

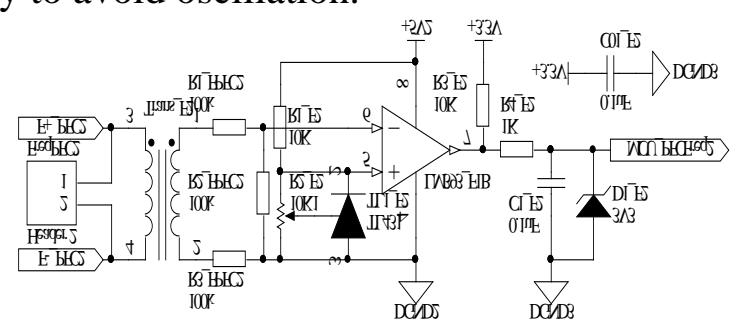

Fig.4 Input voltage frequency detection circuit

\subsection{DC voltage and current conditioning circuit}

DC voltage signal conditioning circuits, and DC current signal conditioning circuit, respectively, as shown in Fig. 5 and 6. DC voltage across the resistor divider, is followed by a voltage through the low-pass filter into the sampling. DC current signal is fed through a resistor converts the sampled signal into a voltage signal is amplified by an amplifier voltage.

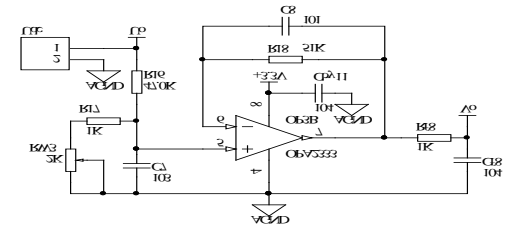

Fig.5 DC voltage signal conditioning circuit

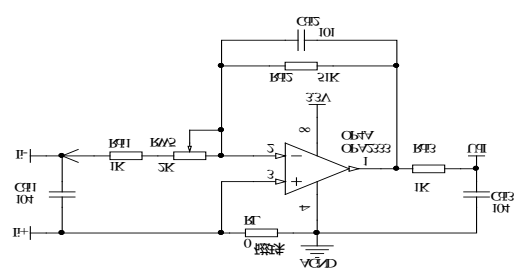

Fig. 6: DC current signal conditioning circuit

\section{Testing and Conclusion}

\subsection{Frequency tracking range test}

Test method: When the system is working at UPS status, input standards vary between $40 \mathrm{~Hz}-60 \mathrm{~Hz}$ sine wave test output voltage frequency. The test results are shown below.

\begin{tabular}{c|c|c|c|c|c}
\hline Source Frequency(Hz) & 41.987 & 48.667 & 50.001 & 56.325 & 60.010 \\
\hline $\begin{array}{c}\text { System output } \\
\text { frequency(Hz) }\end{array}$ & 41.863 & 48.644 & 49.983 & 57.432 & 59.987 \\
\hline
\end{tabular}

\subsection{Output voltage accuracy test}

Test mode: Set the output voltage of $10 \mathrm{~V}$ and $20 \mathrm{~V}$, respectively, under the circumstances, in order to adjust the size of the load change from $10 \Omega-30 \Omega$ measuring voltage stabilization accuracy. Regulation accuracy of test data in the table below, showing the system stable within $1 \%$. 


\begin{tabular}{c|c|c|c|c|c}
\hline Load size & $10 \Omega$ & $15 \Omega$ & $20 \Omega$ & $25 \Omega$ & $30 \Omega$ \\
\hline $\begin{array}{c}\text { Set the output voltage } \\
\text { of } 10 \mathrm{~V} \text { size }\end{array}$ & $9.99 \mathrm{~V}$ & $9.98 \mathrm{~V}$ & $10.02 \mathrm{~V}$ & $10.05 \mathrm{~V}$ & $10.06 \mathrm{~V}$ \\
\hline $\begin{array}{c}\text { Set the output voltage } \\
20 \mathrm{~V}\end{array}$ & $9.91 \mathrm{~V}$ & $9.94 \mathrm{~V}$ & $9.96 \mathrm{~V}$ & $10.00 \mathrm{~V}$ & $10.01 \mathrm{~V}$ \\
\hline
\end{tabular}

\subsection{PFC input power factor and waveform distortion measurement}

Enter the job at PFC modes, respectively, under different load conditions, power factor and waveform distortion test data obtained in the table below, it can be seen from the table, power factor close to 1 , waveform distortion rate.

\begin{tabular}{c|c|c|c|c}
\hline Input Current & $2 \mathrm{~A}$ & $1.5 \mathrm{~A}$ & $1 \mathrm{~A}$ & $0.5 \mathrm{~A}$ \\
\hline Power Factor & 0.97 & 0.99 & 9.98 & 9.98 \\
\hline Waveform distortion rate & $5 \%$ & $3.1 \%$ & $2.1 \%$ & $1.0 \%$ \\
\hline
\end{tabular}

\section{Conclusion}

After more than hardware and software design and test test test frequency tracking range, the output voltage accuracy test, PFC input power factor and waveform distortion measurement, the error is within the allowable range. In the PFC link, the power factor was close to 1.

For maximum frequency point tracking function, not by changing the source impedance and load, the relative deviation test was very small, the absolute value of only $0.6 \%$.

\section{References}

[1] SU Ran.Zhang Lie-yong. Gu Xue-ping. Li He-peng. Li Ran. The distributed fault diagnosis of power network combined with rough set rule mining algorithm[J]. Chinese Journal of Electrical Engineering Engineering. 2010 .30(03):28 -32.

[2]Ren Hui, Mi Zeng-qing, Zhao Hong-shan. Fault diagnosis model for power system based on coding PETRI net. [J]. Chinese Journal of Electrical Engineering Engineering, 2005, 25(20): 44-49

[3] Wen Ming. Dynamic voltage restorer. Voltage sag compensation algorithm to improve its performance[D]. Changsha University of Science and Technology master degree thesis.2012

[4] Zhou Hui, Qi Zhiping. A review of detection methods and compensation strategies for dynamic voltage restorer[J]. Power network technology, 2006, 30 (6): 23-29.

[5] Wang Li Research on active power grid connected inverter for distributed grid[D]. Nanjing University of Aeronautics \& Astronautics master degree thesis.2013.

[6] Li Tai. Study on Dynamic Voltage Restorer Based on flywheel energy storage[D]. Southwest Jiao Tong University master degree thesis.2008. 